\title{
Developing Completion Criteria for Native Ecosystem Reconstruction - A Challenge for the Mining Industry
}

\author{
O.G. Nichols Australian Centre for Minerals Extension and Research, Australia
}

\section{INTRODUCTION}

Companies throughout Australia and in other countries are increasingly adopting an objective of establishing a sustainable native ecosystem following mining. This raises significant issues associated with the mine closure process, specifically in relation to developing and meeting completion criteria for this native ecosystem rehabilitation - will the regulators and the broader community accept defined standards as part of an overall mine closure plan, so that if met, they will agree to lease relinquishment?

Early attempts to set specific completion criteria, for example in the mineral sand mining industry, resulted in targets that were not based on what was known to be achievable using current accepted best practicable rehabilitation methods. As a result, a detailed review of rehabilitation monitoring methods and data at RGC Mineral Sands Eneabba mine was undertaken in 1996 and revised criteria were developed (Nichols, 1996; Peterson et al., 1996). Difficulties with establishing specific criteria for mine rehabilitation in semi-arid areas of the WA Goldfields were also encountered by Brearley and Osborne (2000).

Both regulatory authorities and mining companies are now addressing this issue across Australia, but there are still relatively few examples of mine closure strategies that have been through a full public and technical review process and then been signed off by both the mining company and all regulatory authorities.

Recent examples from Australian mining projects in different parts of the country demonstrate that significant progress has been made in relation to the development of achievable ecological completion criteria. Detailed work has been conducted at Alcoa World Alumina's bauxite mines in WA (Nichols et al., 2005), mines in the goldfields of WA (Brearley and Osborne, 2000), coal mines in Queensland's Bowen Basin and NSW's Hunter Valley (Nichols 2004, 2005), CRL's heavy mineral sand mine on North Stradbroke Island, Queensland (Nichols and Foot, 2002) and other mines. This paper reviews the approaches these companies have taken, and by focusing specifically on the coal mining studies, illustrates principles that could be adapted to a wide range of situations where the goal is to establish a sustainable native ecosystem following mining.

\section{OVERVIEW OF THE PROCESS USED TO DEVELOP COMPLETION CRITERIA}

A process for developing completion criteria suited for coal mines in Queensland and New South Wales evolved from two projects funded by the Australian Coal Association Research Program (ACARP). The objective of these projects was to develop an agreed, workable process for addressing relevant issues relating to mine closure and associated completion criteria when establishing native vegetation communities following coal mining. The projects were intended to reduce the uncertainty relating to completion criteria for native ecosystem establishment. The full reports (Nichols 2004, 2005) should be consulted as they explain the process used in great detail.

Both projects involved conducting a search of published and unpublished literature to review processes that have worked elsewhere, and visiting numerous coal mines to discuss relevant mine closure issues. As the process evolved, case studies were used to illustrate how it should work in practice. One of these case studies was the Westside coal mine in NSW, and elements of this study are described later to illustrate specific detail. 
The process developed involved integrating a number of key components related to the establishment, monitoring and management of rehabilitation. These are described in more detail in Nichols $(2004,2005)$ and also in Nichols et al. (2005) and consist of:

- Setting attainable objectives based on what can be achieved using good practice rehabilitation, allowing for site and technical limitations, and adopting a whole-of-lease perspective.

- Implementing monitoring and research programs that will facilitate continuous improvement in rehabilitation standards, and reveal how the ecosystem is developing. This should include monitoring of unmined reference sites for comparison, the use of indicators to assess key aspects of ecosystem development, and the assessment of long-term sustainability under the proposed management regime.

- The coal mining projects recommended that a number of general procedures should be followed when developing the specific completion criteria. These are:

- Consultation with all relevant stakeholders is an essential component of the development of agreed completion criteria.

- Where appropriate, the criteria should include both prescriptive criteria (to confirm that certain actions have been carried out) and performance criteria (to confirm that rehabilitation has attained an agreed target or standard).

- Criteria should be divided into stages of the operation, viz. planning, establishment, development and signoff, and post-relinquishment monitoring and maintenance.

- Development of criteria, standards and milestones should, where possible, be an iterative process, with initial general criteria set, cost-effective best practice rehabilitation implemented, results monitored, and the criteria revised according to what monitoring and research show to be achievable (Figure 1).

- When finalised, completion criteria should be thought of as 'trigger levels'. Failure to meet them should 'trigger' an internal investigation into the likely causes, and a risk assessment. A joint decision on whether to implement remedial action(s) should be made by the company and the relevant regulatory authority.

- Completion criteria, standards and milestones should be reviewed regularly (e.g. every 5 years) and, where necessary, revised by mutual agreement between the company, key stakeholders and the regulatory authority, to take account of significant advances in costeffective rehabilitation techniques.

- Post-closure and post-relinquishment monitoring and management requirements need to be clearly determined, and both the responsibility for implementing them, and funding sources, clearly defined.

Specific details of key elements of the above process are discussed in detail below.

\section{SETTING OBJECTIVES}

Specific rehabilitation objectives, developed in conjunction with regulators and other key stakeholders, are an essential component of the process for developing completion criteria. The process used for developing achievable and specific rehabilitation objectives is illustrated by the Westside mine case study (Nichols, 2005).

Westside is an open cut coal mine located in the Newcastle Coal Basin, approximately $20 \mathrm{~km}$ southwest of Newcastle NSW. The mine is managed by Oceanic Coal Australia Limited (OCAL), part of the Xstrata group. Mining operations commenced in 1992, with mining in the Northern Pit being completed in 1998, and operations in the Southern Pit and the new East Pit likely to be completed around 2010. Westside is a relatively small mine. 


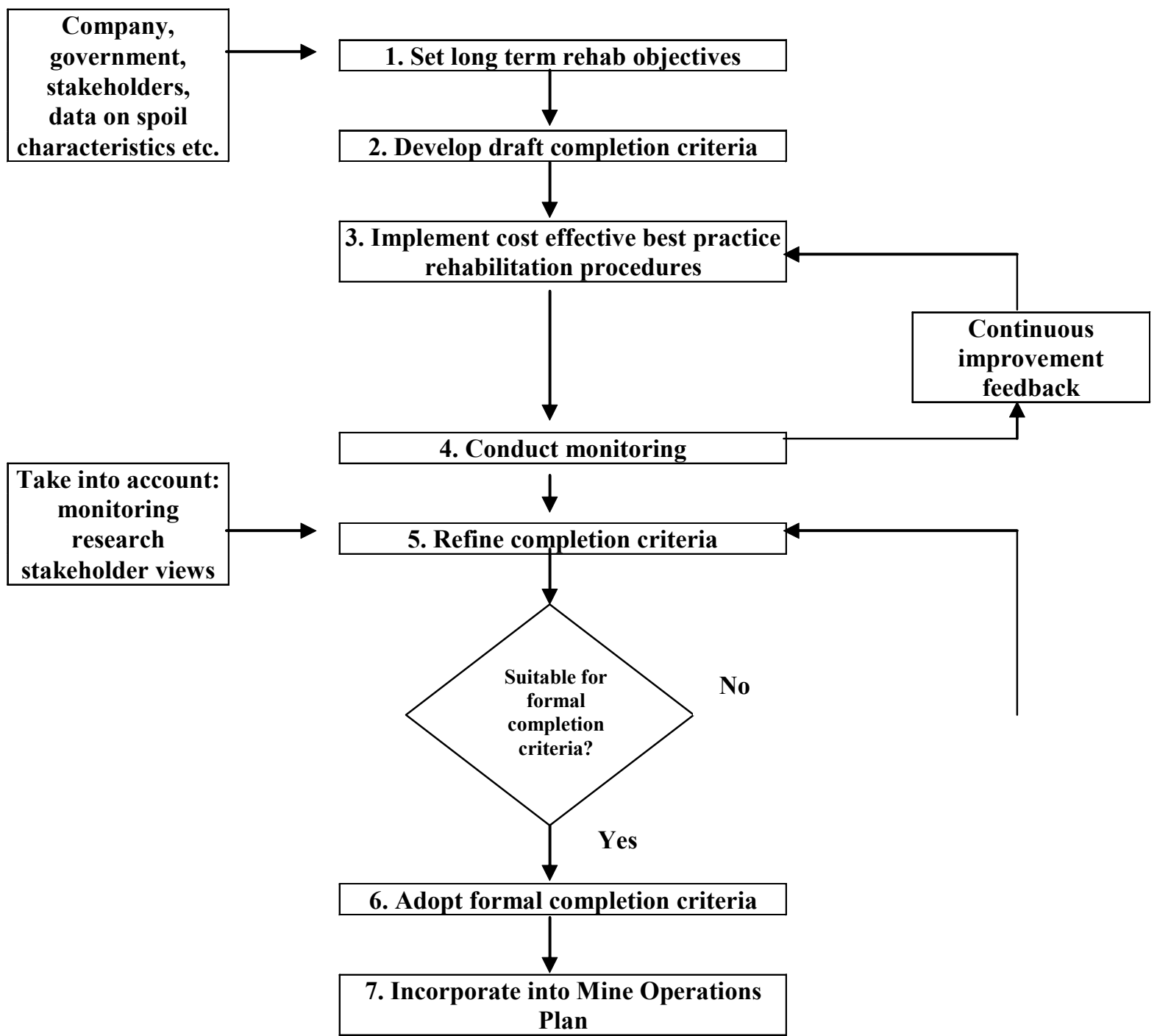

\section{Figure 1 Suggested flowchart used to develop completion criteria}

At the completion of mining operations, a total of 147 ha will have been cleared and 123 ha rehabilitated. A detailed description of rehabilitation methods is given in Nichols (2005).

The mine is predominantly located in an area of remnant forest/woodland that includes Smooth-barked Apple (Angophora costata)/Red Bloodwood (Corymbia gummifera)/Mahogany (Eucalyptus umbra) Association, Scribbly Gum (E. signata)/Stringybark (E. eugenioides and E. capitellata) Association and two Swamp Open Forest Associations. Both of the latter are listed as an Endangered Ecological Community on Part 3 of Schedule 1 of the NSW Threatened Species Conservation Act 1995 (Sydney Coastal Estuary Swamp Forest Complex). However, planned mining operations will impact mainly on those communities not listed as Threatened. Other important conservation values include the presence of Black-eyed Susan (Tetratheca juncea), a flora species currently listed on Schedule 2 of the above Act, in the southern extension area, and three threatened fauna species (Common Bent-winged Bat (Miniopteris schreibersii), Little Bentwinged Bat (Miniopteris australis) and the Squirrel Glider (Petaurus norfolcensis)).

The remnant forest and woodland shows evidence of a variety of disturbances including recent fire, as well as previous mining activities, grazing, and human disturbance (e.g. firewood collecting). The small village of Killingworth is less than $1 \mathrm{~km}$ north of the mine, with small rural properties located south-east of the mine. 
A specific rehabilitation objective was developed following discussions with company staff. This is summarised below, and takes into account surrounding land use and conservation values, what might be achievable using good practice rehabilitation, any site or technical limitations, and post-mining management requirements. It provides specific detail and direction, and forms the basis for continuing development of the rehabilitation monitoring program and completion criteria to determine whether the objective has been met.

The overall objective of rehabilitation following mining at Westside, as described in Nichols (2005), is 'to establish a stable, self-sustaining native forest and woodland ecosystem that fulfils designated land uses including protection of water quality and nature conservation, and which:

- Represents what can be achieved using cost-effective rehabilitation procedures that reflect mining industry current best practice.

- Reflects the composition of pre-mining communities and representative unmined reference sites, and fulfils similar functions.

- Provides habitat for a range of native fauna species, including, where practicable, Threatened Species.

- Is based on the findings of relevant research into the establishment of biodiversity, ecosystem function, and sustainability.

- Is compatible with Westside's overall whole-of-lease land management approach, which includes a Voluntary Conservation Agreement for conservation of Sydney Coastal Estuary Swamp Forest and Tetratheca juncea, management of other remnant bushland on the mining lease, and identified opportunities for rehabilitation of degraded areas where practicable e.g. the Old Millers Rhondda Open Cut area.

- Takes into account the views of the Westside Community Consultative Committee and other relevant stakeholders.

- Results in either no measurable or acceptable off-site impacts.

- Management requirements (e.g. maintenance of access tracks, fire) are not greater than those of areas prior to mining, or where extra management actions may be required, a mechanism has been put in place for addressing these'.

This objective the company will aim to achieve not only takes into account the need to meet Westside's regulatory requirements, but also identifies opportunities for enhancing conservation values through the Voluntary Conservation Agreement, and rehabilitation of degraded areas at a previous open cut mine.

It is intended that the rehabilitation objective and associated completion criteria and target standards will be reviewed by Westside and regulatory authorities after five years, and if necessary, revised by mutual agreement. This review should enable the incorporation of any advances in cost-effective rehabilitation techniques.

\section{MONITORING AND RESEARCH}

Monitoring and related research programs are essential components of the process of setting achievable completion criteria. The principal purposes of monitoring and research (ICMM 2005), all of which are directly relevant to completion criteria, are to:

- Act as a quality control checklist to confirm that rehabilitation operations have been carried out according to agreed procedures.

- Provide the data necessary for enabling continuous improvement required as part of an ISO 14001compatible EMS. This will include both monitoring data on rehabilitation performance ('how is it going?'), and research data comparing methods of biodiversity establishment ('how can we improve it?').

- Reveal to the company and key stakeholders whether rehabilitation objectives are being met - or will be within an acceptable time frame. 
- Assess long-term sustainability of rehabilitated areas under the proposed management regime.

Good rehabilitation monitoring programs must therefore be designed in a manner that ensures they will fulfil the above purposes, as well as taking into account the practicalities of monitoring, cost and safety. They should contain the following four linked components:

- Baseline and ongoing monitoring of unmined reference areas established during pre-mining mapping and surveys, to identify and monitor values that need to be protected or replaced.

- Documentation of the rehabilitation procedures carried out; this is critical for interpreting the findings of later rehabilitation monitoring results.

- Initial Establishment Monitoring, which serves as a Quality Control step. It is carried out soon after rehabilitation establishment operations have been completed, and records whether they have been carried out as required, and initial establishment success.

- Long Term Monitoring, which usually commences around 2-3 years, evaluates the progress of rehabilitation towards fulfilling long-term land use objectives. Together with key research projects, it provides the information needed to determine whether the rehabilitated ecosystem is likely to be sustainable.

When designing the monitoring program, the following details should always be addressed (ICMM, 2005):

- Incorporate the principles of experimental design, ensuring that it is statistically valid where possible.

- Carefully select the parameters or indicators that, in combination, will provide the information the mining company and other stakeholders require to assess rehabilitation performance and sustainability. They should include measures of how the site is developing in the following key areas: soil physical properties; soil chemical characteristics (both limiting factors and fertility); soil biota; vegetation establishment, growth, function, floristics, recruitment and recovery; and fauna (vertebrates and invertebrates).

- Select and monitor suitable reference sites, where possible. These should be located in unmined areas typical of the habitat affected, and that which is being restored or established, but safe from further mining disturbance. Monitoring reference sites provides ecosystem function and biodiversity information from a site likely to be functioning sustainably.

- Consider links to other monitoring programmes (e.g. soil development, nutrient cycling, fauna monitoring, timber and agricultural production) and also to research projects. In general, a key purpose of rehabilitation monitoring is to identify any problems, while targeted research should then find ways of overcoming them.

Based on the above factors, a suitable, cost-effective monitoring program should be designed and implemented, ensuring that there is sufficient commitment, skills and resources in the company for it to be carried out.

Westside mine's recommended rehabilitation monitoring program is described in Nichols (2005). The monitoring program developed in conjunction with previous and current research projects, is designed to enable Westside and other stakeholders to assess whether the objectives described earlier have been met, and the completion criteria have been fulfilled. Relatively detailed research on ecosystem development previously conducted at the mine has been taken into account in the design of the monitoring program, which, in some aspects, is less detailed than that which would be required at some other mines, due to the extensive amount of information available. The recommended rehabilitation monitoring program consists of two components:

- General rehabilitation assessment monitoring; this is designed to assess the progress of rehabilitated ecosystems and provide information for continuous improvement.

- Rapid assessment prior to signoff; intended to confirm that all completion criteria listed in the following section have been fulfilled prior to closure and relinquishment. 
The recommended design for general rehabilitation assessment monitoring consists of plots established in a range of different rehabilitation ages and types, and also in two unmined reference sites. The $20 \mathrm{~m} \times 10 \mathrm{~m}$ plots are used to measure numbers and growth of larger trees, and take soil samples, whilst five $2 \mathrm{~m} \times 2 \mathrm{~m}$ quadrats within them are used to obtain detailed data on plant species richness, abundance and cover. This combination of biodiversity, growth and functional measures will enable Westside to assess long-term ecological trends, and for key parameters, if required, the company will be able to statistically compare any site with itself over time, or with other rehabilitated and reference sites.

When it is thought that a rehabilitated unit is ready for signoff, a Rapid Assessment Procedure will be undertaken. This involves collating all available information, confirming that rehabilitation operations have been carried out as required, assessing the site using monitoring and research data, and conducting a site inspection with regulatory authorities.

Research carried out by Alcoa demonstrates how important this can be in relation to the setting and attainment of achievable completion criteria. For example, the company has focused considerable research effort on continuous improvement of the rehabilitation techniques used to establish a jarrah forest ecosystem (Nichols 2003). Key research areas have related to ripping, topsoil handling, fertilizing and seeding. Any cost-effective improvements developed have been incorporated into rehabilitation prescriptions. Successional studies have investigated the development of floral and faunal communities over time (e.g. Ward et al., 1990; Grant, 2003; Nichols, 1998, 2003; Nichols and Nichols, 2003; Grant, 2005). These found that the initial plant species established dominate the vegetation community of a site for a very long time, and led Alcoa to realise the importance of establishing a diversity of species at the start, thus resulting in more effort being put into the research on topsoil handling and seeding methods described above. Detailed fauna studies have focused on groups that indicate key aspects of biodiversity and ecosystem function such as birds (vegetation structure, floristics and insect abundance), reptiles (presence of ground shelter and invertebrates), spiders (vegetation structure and suitable prey), ants (pollination, soil aeration), collembola, mites and termites (nutrient cycling). Together, these studies have provided a detailed understanding of ecosystem development, and enabled Alcoa to develop and set criteria that meet the expectations of regulators and other stakeholders.

\section{DEMONSTRATING SUSTAINABILITY}

Long-term ecosystem sustainability is a key issue that must be incorporated into any set of completion criteria. This is because an understanding of how sustainable the rehabilitated ecosystem is likely to be under nominated management practices is critical for determining whether regulators are willing to agree to lease relinquishment, and also for deciding what level and detail of post-closure management input will be required. Sustainability under likely perturbations such as drought and fire must also be demonstrated. For these reasons, considerable thought has been given to what might be the best methods of assessing whether a rehabilitated ecosystem will be sustainable over the long-term.

A sound understanding of long-term trends and ecosystem processes occurring in rehabilitation is the best way of determining how sustainable a native ecosystem is likely to be. For example, a well designed longterm monitoring program will give an indication of the sustainability of the vegetation community over time by revealing whether, for particular parameters measured:

- It appears to be relatively stable over time, although there will be fluctuations due to seasonal variations, drought, fire, etc.

- It is within the range of values recorded in unmined reference sites (the assumption being that the reference site is sustainable).

- It meets critical target values based on previous research findings.

There is no single 'quick fix' indicator which unequivocally demonstrates that a rehabilitated native ecosystem will be sustainable. Key aspects of ecosystem development must be measured and understood in order to fully assess long-term ecosystem sustainability. These can include soil physical and chemical development, plant water relations, soil microbiology, faunal ecology, and the effects of fire, drought and sustainable utilisation (e.g. timber harvesting, managed grazing). 
Recognising this, Alcoa's approach to demonstrating sustainability of the developed ecosystem has focused on interpreting and understanding the findings of the successional and nutrient cycling studies described below (Nichols et al., 2005). The rehabilitated ecosystem is considered likely to be sustainable if it matches the unmined forest in key aspects, and/or no problems are apparent. Thus, rehabilitation that matches the unmined forest in plant species richness and ecological function, and supports comparable populations of key faunal groups, is considered likely to be sustainable.

The detailed research projects conducted by Alcoa and described earlier have given a good indication of how sustainable bauxite mine rehabilitation is likely to be, and what long-term management will be required. For example, nutrient cycling research has been carried out to determine whether the nutrient bank is sufficient for a mature forest to develop, and if so, whether the nutrients will be available to plants when required (Ward et al, 1990). Other specific projects have related to studies on tree growth, biomass, litter breakdown, leaf tissue analysis, soil microbiology and development of the soil profile (Nichols, 1998; 2003).

Resilience of rehabilitation to natural or man-induced perturbations is also a key element of ecosystem sustainability. Alcoa researchers have studied resilience of the rehabilitated forest ecosystem to fire in great detail. Fire is a recurring element of the jarrah forest ecosystem, and it is essential that the rehabilitated mines can be managed in conjunction with the surrounding forest using managed burning prescriptions. Vegetation studies have monitored the post-burning response of a range of parameters including fuel load, tree growth, plant density, live plant cover, species richness, weed response, Acacia density and cover (Grant et al., 1997; Grant et al., 1998; Smith et al., 2000; Grant, 2003; Smith et al., 2003). More recent studies have examined the impact of prescribed burning on nutrient pools in rehabilitated areas (Morley et al., 2003). Detailed fauna studies have also been conducted to assess the response of vertebrate (Nichols and Nichols, 2003) and invertebrate (Brennan, 2002) fauna to burning. As a general rule, these studies show good recovery of key components of the rehabilitated forest ecosystem following fire. Together, this understanding has enabled the WA Government and other stakeholders to confidently sign off on an agreed mine closure process.

In less predictable environments, such as the WA Goldfields and Queensland's Bowen Basin, it is important to measure a range of parameters and develop an understanding of likely successional trends under different scenarios of variable rainfall, drought, and fire. Elements of the approach used by Brearley and Osborne (2000) and Brearley (2003) may be relevant for some mines. This study monitored trends in a number of key vegetation and soil parameters, and demonstrated that they were heavily influenced by the amount and timing of rainfall. They concluded that, even under a prescribed rehabilitation formula, the resultant revegetation outcome cannot be predicted with a high level of certainty. Instead, they proposed that the focus should be on trends rather than on specific quantitative targets. They also pointed out the importance of resilience, and recommended that two indicators of resilience should be used, viz. high quality and germination of progeny seed, and ability to recover from disturbances including drought, fire, and overgrazing. And finally, they noted the importance of diversity, by illustrating that planting of species with similar life cycle patterns could result in all senescing around the same time, with a significant impact on the structure and composition of the revegetation. The above aspects were linked by suggesting a system of staged completion criteria and associated standards.

Successional models such as those described by Grant et al. (2001) and Noble and Slatyer (1980); see also Morrison et al., 2005 for an illustration of how this might work in practice) may also prove useful in determining whether particular desirable stages have been reached, and what improvements to rehabilitation establishment and management programs may be needed. As these models are developmental, they should only be used with care, and a sound understanding of their likely limitations and deliverables.

Ecosystem Function Analysis (EFA) is another procedure some mines in different regions of Australia are using to assess likely sustainability. The technique was developed by CSIRO as part of an industry and government-funded ACMER project (Tongway, 1999). It is intended to be a rapid assessment technique for measuring the development of ecosystem processes and long-term sustainability. EFA consists of three components, viz. Landscape Function Analysis (LFA), which assesses soil development and stability; Vegetation Dynamics, which monitors development of vegetation; and Habitat Complexity, which assesses fauna habitat. 
Development of the ecosystem is measured by using EFA to compare rehabilitated versus analogue (or reference) sites, different aged rehabilitated sites, the same rehabilitated sites over time, and sites rehabilitated using different techniques. Most research and monitoring effort has focused on the LFA component of EFA.

LFA has not been used routinely by any mine in the Hunter Valley. However, investigations into its suitability as a monitoring tool have been carried out at a number of Hunter Valley coal mines. A study by Robertson (2002) investigated one key aspect of the procedure, by comparing the LFA nutrient cycling index with a number of microbial measures widely accepted as indices of nutrient cycling. Results of LFA surveys and microbial indices were compared over a range of substrate/vegetation rehabilitation types including spoil/pasture, spoil/woodland, topsoil/pasture, and chitter/woodland. Strong linear relationships were found between LFA and some microbial indices for pasture rehabilitation; however for woodland rehabilitation, the relationships were not as strong.

In Queensland, LFA is currently used on Xstrata coal mines, and the monitoring program implemented at Oaky Creek in 2003 will provide valuable information on its suitability for use at that site. LFA is also being used as part of an honours project being conducted at Anglo Coal's Callide mine. Both LFA and EFA tend to be more widely used in WA, particularly in the Goldfields. However, discussions held by O. Nichols with WA regulators indicated that they see LFA not as a stand-alone signoff procedure, but rather as one of a set of tools that collectively can be used to demonstrate that a site is sustainable and is likely to meet land use objectives.

A verification project conducted by the Australian Centre for Minerals Extension and Research noted that the technique worked well at some mines, but at others, not all components could be verified (Tongway and Hindley, 2003; Seaborn, 2003). Mulligan and Grigg (2003) concluded that the LFA approach has value as one of a number of tools used for monitoring rehabilitation success. Companies considering using EFA should consult all of the above reports to ensure that they understand the procedure's strengths and weaknesses.

Being a rapid assessment procedure, EFA tends to focus on ecological processes, while long-term monitoring programs used by companies such as Alcoa and CRL (Nichols and Foot, 2002) focus on both understanding successional processes, and on the re-establishment of biodiversity. Any rehabilitation designed to establish a sustainable native ecosystem must take biodiversity into account to an extent that depends on the specific mine's objectives. One limitation of the procedure is the fact that LFA does not measure soil nutrient levels, relying instead on describing likely trends in nutrient accumulation or loss. This could mean that deficiency of a key element such as $\mathrm{P}$ may not be detected until rehabilitation performance is clearly affected. Finally, the subjective assessment of some components of the LFA procedure means that great care needs to be taken to ensure that inconsistencies do not occur between those conducting the assessment.

In summary, each mine needs to give consideration to what methods will be used to demonstrate that rehabilitation will be sustainable under the proposed land use and all likely scenarios (e.g. fire, drought), and what level of management will be required. Discussions with regulatory authorities, research institutions and other key stakeholders should help in this regard.

\section{DEVELOPING COMPLETION CRITERIA}

Selected completion criteria developed for Westside are shown in Appendix 1, with the full criteria in Nichols (2005). It should be emphasised that these only apply to the establishment of native ecosystems and related rehabilitation aspects, and therefore only constitute part of the overall mine closure plan. The table takes into account all identified indicator categories and is based on a staged approach, which requires that the mine meets defined standards or milestones at the following stages:

- Planning - this requires that all objectives, procedures, landform plans, monitoring and research programs have been developed to the satisfaction of regulatory authorities.

- Establishment - this requires that all rehabilitation has been carried out according to agreed procedures, and appropriate records kept. 
- Development and sign-off stage - this sets required standards and milestones for the developing ecosystem, focusing on key aspects and indicators relating to vegetation, fauna, landform stability, soils and land use.

- Monitoring and maintenance - this addresses post-closure and post-relinquishment issues relating to monitoring, management, ownership and liability, funding and risk assessment.

The types of criteria listed vary in detail. Some require that certain actions be carried out, such as ripping and topsoil spreading, and auditable records be retained to verify they have been done. Others may require detailed research and monitoring in specific areas, such as those demonstrating that nutrient cycling processes are proceeding satisfactorily, or total soil erosion rates do not exceed a stated rate. Some criteria are designed to be verified by the monitoring program described in the previous section. And finally, some criteria require that mechanisms be in place for addressing relevant post-closure and post-relinquishment issues, ensuring that, once all criteria have been met, Westside will have no ongoing liability in relation to rehabilitation establishment.

\section{FUTURE CHALLENGES}

The mining industry still faces some significant challenges in relation to setting completion criteria for native ecosystem rehabilitation. In areas where rainfall is unpredictable, trends in most ecological parameters do not follow the classic pattern observed in more mesic environments. Unmined, largely undisturbed native vegetation communities can include large bare areas, so percentage cover is not always a good predictor of sustainability. More work is needed in arid and semi-arid environments in order to develop achievable completion criteria and good measures of likely future sustainability.

New initiatives encouraging mines to undertake progressive rehabilitation are being implemented in Queensland (EPA, 2005) and being considered in other states. These will require that mining companies, regulators and other stakeholders give due consideration to what completion criteria might be applicable to particular stages and domains of a mining operation.

Progressive mining companies are taking a whole-of-lease perspective to rehabilitation of biodiversity values (Nichols and Bell, 2005), sometimes in conjunction with offsets and conservation banking. Most Australian states now either have environmental or biodiversity offsets policies, or are developing them. One of the greater challenges facing the implementation of these policies is the matter of metrics, or how to assess the value of offsets. Related to this is the question of completion criteria; if a degraded area is rehabilitated as part of an offset package, criteria need to be developed to determine when the offset objectives have been fulfilled.

All of the above, and other challenges that will undoubtedly arise, mean that the development of workable completion criteria for native ecosystem rehabilitation will continue to be an evolving process.

\section{CONCLUSIONS}

The procedures and examples discussed in this paper illustrate a number of key aspects that should be taken into account by any mining operation when developing completion criteria for sustainable native ecosystem rehabilitation. They emphasise that the setting of overall objectives and completion criteria should be a consultative process involving the mining company, regulatory authorities, local community and any other relevant stakeholders. The objectives, as well as specific targets and standards, should only represent what can be achieved using recognised cost-effective good practice rehabilitation. The setting of criteria will often need to be an evolving process: implement good practice rehabilitation, measure key indicators, develop more specific targets based on what is shown to be achievable, and integrate these into the mine closure plan.

Monitoring and research are critical components of the whole process, in terms of ensuring continuous improvement, developing completion criteria, and determining whether they have been met. A key element of this is the assessment of rehabilitated ecosystem sustainability, which must be based on sound monitoring data, and must apply to the specified post-mining land management practices.

The conclusions of the Queensland and New South Wales completion criteria projects are summarised in 13 general principles (Nichols, 2005). The approach used has been accepted by mines and regulators in both 
states. Experience at a number of mines in Australia has demonstrated that, if these principles and the procedures described in this paper are followed, achievable completion criteria can be developed, resulting in sustainable rehabilitation and a streamlined mine closure process.

\section{ACKNOWLEDGEMENTS}

Some of the information in this paper was derived from projects funded by the Australian Coal Association Research Program, with further funding and assistance in-kind from coal mining companies including Xstrata and Westside mine. The work took place whilst the author was Research Program Manager at the Australian Centre for Minerals Extension and Research. The support of these organisations is gratefully acknowledged.

\section{REFERENCES}

Brearley, D.R. and Osborne, J.M. (2000) Developing completion criteria for minesites in arid and semi-arid WA. In 2000 Workshop on Environmental Management in Arid and Semi-Arid Areas Proceedings. Goldfields Land Rehabilitation Group, Boulder, WA, pp. 11-21.

Brearley, D. (2003) Developing Completion Criteria for Rehabilitation Areas on Arid and Semi-arid Mine Sites in Western Australia. PhD Thesis, Curtin University of Technology, Perth.

Brennan, K. (2002) The Successional Response of Spider Communities Following the Multiple Disturbances of Mining and Burning in the Western Australian Jarrah Forest. PhD Thesis, Curtin University of Technology, Perth.

EMRC (1996) A review of RGC Mineral Sands flora and fauna monitoring program at Eneabba. Consulting report prepared for RGC Mineral Sands, Eneabba, Western Australia.

Gardner, J. (2001) Rehabilitating bauxite mines to meet land use objectives: bauxite mining in the jarrah forest of Western Australia. Unasylva 52, pp. 3-8.

Grant, C.D., Loneragan, W.A., Koch, J.M. and Bell, D.T. (1997) Fuel characteristics, vegetation structure and fire behaviour of 11-15 year-old rehabilitated bauxite mines in Western Australia. Australian Forestry 60 (3): pp. 147-157.

Grant, C.D., Koch, J.M., Smith, R.D. and Collins, S.J. (1998) A review of prescription burning in rehabilitated bauxite mines in Western Australia. CALMScience 2 (4), pp. 357-371.

Grant, C.D., Duggin, J., Meek, I. and Lord, M. (2001) End point criteria and successional pathways for manganese mining rehabilitation on Groote Eylandt, NT. Presented at the Minerals Council of Australia Workshop, Adelaide.

Grant, C.D. (2003) Post-burn vegetation development of rehabilitated bauxite mines in Western Australia. Forest Ecology and Management 186, pp. 147-157.

Grant, C.D. (2005) State-and-transition successional model for bauxite mining rehabilitation in the Jarrah Forest of Western Australia. Restoration Ecology (in press).

ICMM (2005) Good Practice Guidance for Mining and Biodiversity. Draft report prepared for the International Council on Mining and Metals by ERM and ACMER.

Morley, S.C., Grant, C.D., Hobbs, R.J. and Cramer, V.A. (2003) Long-term impact of prescribed burning on the nutrient status and fuel loads of rehabilitated bauxite mines in WA. Forest Ecology and Management 190, pp. 227-239.

Morrison, B., Lamb, D. and Hundloe, T. (2005) Assessing the likelihood of mine site revegetation success: A Queensland case study. Australasian Journal of Environmental Management 12(3), pp. 165-182.

Mulligan, D.R. and Grigg, A.H. (2003). Confidence in monitoring rehabilitation outcomes. In Mining and Post Mining Landscapes. What are the environmental risks that matter? Proceedings of a workshop presented by the Environmental Protection Agency in partnership with Sinclair Knight Merz. Rockhampton, 23-24 June 2003.

Nichols, O.G., Koch, J.M., Taylor, S. and Gardner, J. (1991) Conserving biodiversity. Papers of the Australian Mining Industry Council Environmental Workshop, Perth.

Nichols, O.G. (1998) The development of a rehabilitation program designed to restore a jarrah forest ecosystem following bauxite mining in south-western Australia. In Fox, HR and Moore, HM Land Reclamation - Achieving Sustainable Benefits, pp. 315-325, AA Balkema, Rotterdam. 
Nichols, O.G. and Foot, P. (2002) Designing a vegetation monitoring program to achieve continual improvement and assess the long term sustainability of mine rehabilitation. Proceedings of the Minerals Council of Australia Sustainable Development Conference and 27th Annual Environmental Workshop, Newcastle 10-15 November 2002. pp. 79-88.

Nichols, O.G. (2003) Establishing functional native ecosystems following mining - minimising risk by doing the job right. In Mining and Post Mining Landscapes. What are the environmental risks that matter? Proceedings of a workshop presented by the EPA in partnership with Sinclair Knight Merz. Rockhampton, 23-24 June 2003.

Nichols, O.G. and Nichols, F.M. (2003) Long-term trends in faunal recolonisation after bauxite mining in the jarrah forest of south-western Australia. Restoration Ecology 11, pp. 261-272.

Nichols, O.G. (2004) Development of rehabilitation completion criteria for native ecosystem rehabilitation on coal mines in the Bowen Basin. Australian Coal Association Research Program Project C12045.

Nichols, O.G. (2005) Development of rehabilitation completion criteria for native ecosystem rehabilitation on coal mines in the Hunter Valley. Australian Coal Association Research Program Project C13048.

Nichols, O.G., Grant, C. and Bell, L.C. (2005) Developing ecological completion criteria to measure the success of forest and woodland establishment on rehabilitated mines in Australia. Presented at the 2005 National Meeting of the American Society of Mining and Reclamation, June 19-23, 2005. Published by ASMR, 3134 Montavesta Rd., Lexington, KY 40502.

Noble, I.R. and Slatyer, R.O. (1980) The use of vital attributes to predict successional changes in plant communities subject to recurrent disturbances. Vegetatio 43, pp. 5-21.

Seaborn, V. (2003) An assessment of the indices of Landscape Function Analysis on rehabilitated mine sites. Masters Thesis, Centre for Mined Land Rehabilitation, the University of Queensland.

Smith, M.A., Grant, C.D., Loneragan, W.A. and Koch, J.M. (2003) Fire management implications of fuel loads and vegetation structure in jarrah forest restoration of bauxite mines in Western Australia. Forest Ecology and Management 187, pp. 247-266.

Smith, M.A, Loneragan, W.A., Grant, C.D. and Koch, J.M. (2000) Effect of fire on the topsoil seed banks of rehabilitated bauxite mine sites in the jarrah forest of Western Australia. Ecological Management and Restoration 1(1), pp. 50-60.

Tongway, D.J. and Murphy, D. (1999) Principles for designed landscapes and monitoring of ecosystem development in rangelands affected by mining. In VIth International Rangeland Congress Proceedings with International Rangeland Congress Inc. Aitkenvale Queensland, Australia.

Tongway, D.J. and Hindley, N.L. (2003) Indicators of Ecosystem Rehabilitation Success. Stage Two- Verification of EFA Indicators. Final Report for the Australian Centre for Mining Environmental Research. CSIRO Sustainable Ecosystems, Canberra.

Tongway, D.J. and Hindley, N.L. (2004) Landscape Function Analysis: procedures for monitoring and assessing landscapes with special reference to minesites and rangelands. CSIRO Sustainable Ecosystems, Canberra, Australia.

Ward, S.C., Koch, J.M. and Nichols, O.G. (1990) Bauxite mine rehabilitation in the Darling Range, Western Australia. Proceedings of the Ecological Society of Western Australia 16, pp. 557-565.

Ward, S.C., Slessar, G.C. and Glenister, D.J. (1993) Environmental resource management practices of Alcoa of Australia Limited. In J.T. Woodstock and J.K. Hamilton (eds), pp. 104-108. Australasian Institute of Mining and Metallurgy, Parkville, Victoria.

Ward, S.C., Slessar, G.C., Glenister, D.J. and Coffey, P.S. (1996) Environmental resource management practices of Alcoa in southwest Western Australia. In D. Mulligan (ed), pp. 383-402. Environmental Management in the Australian Minerals and Energy Industries - Principles and Practices. UNSW Press, Sydney. 


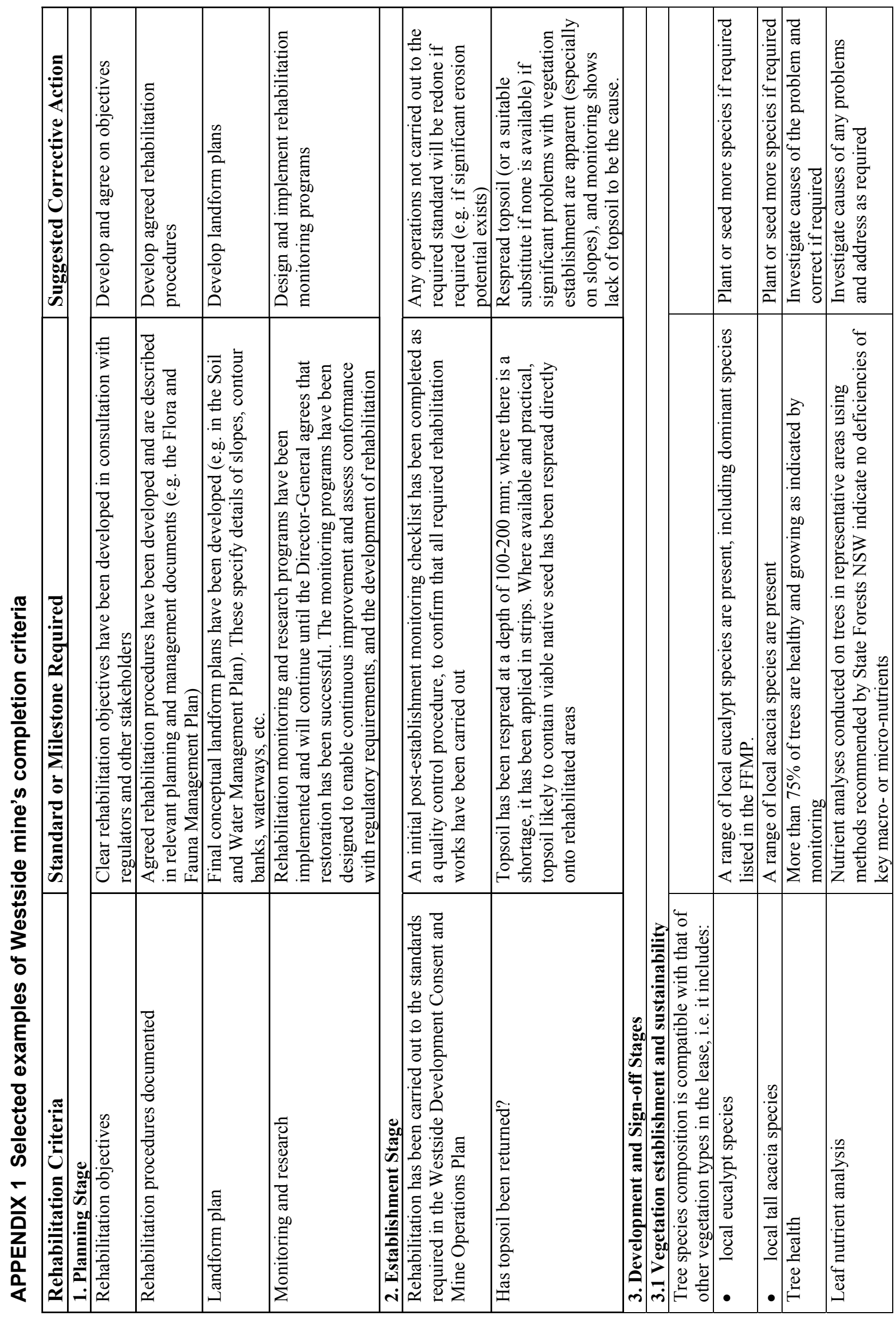




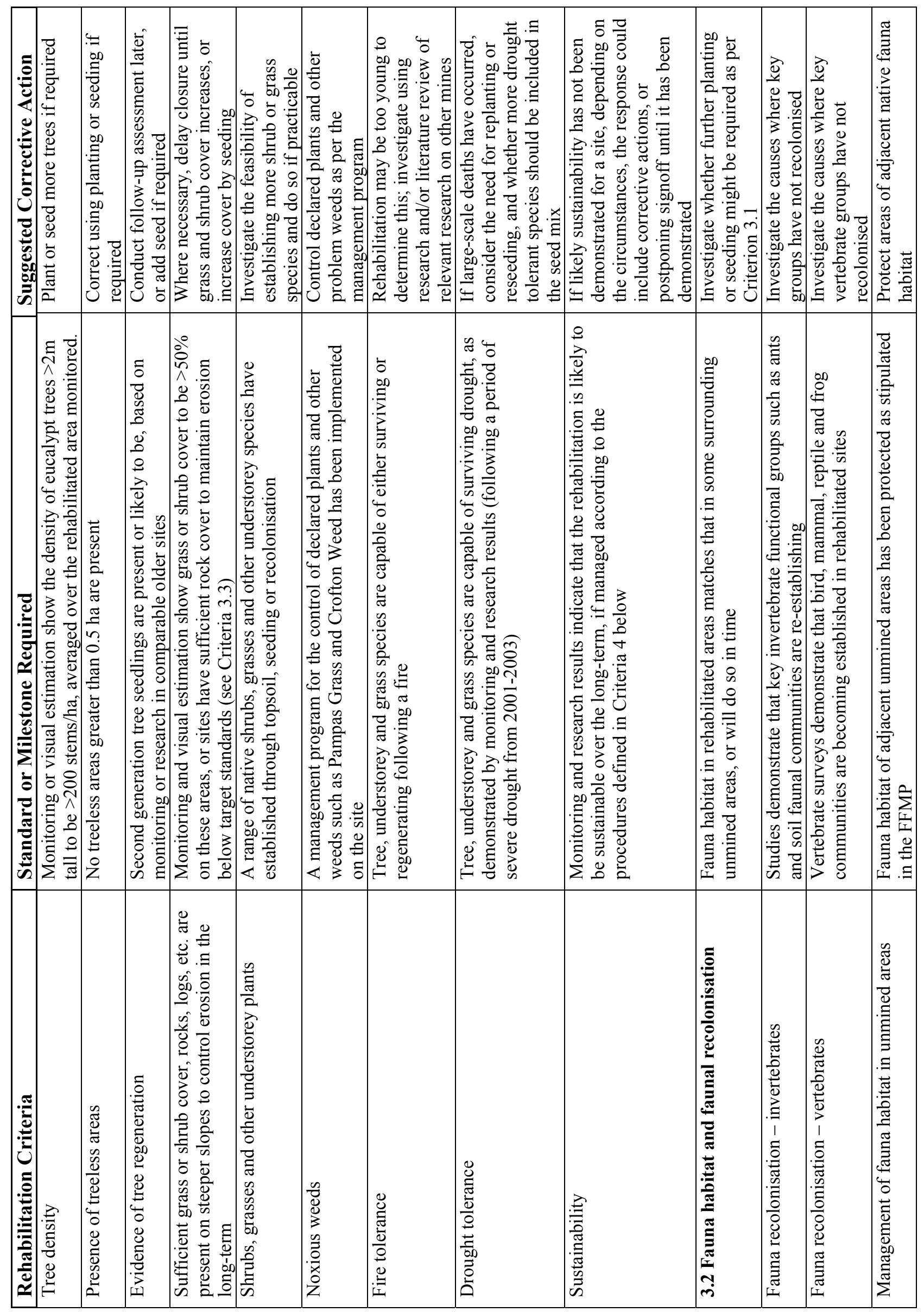




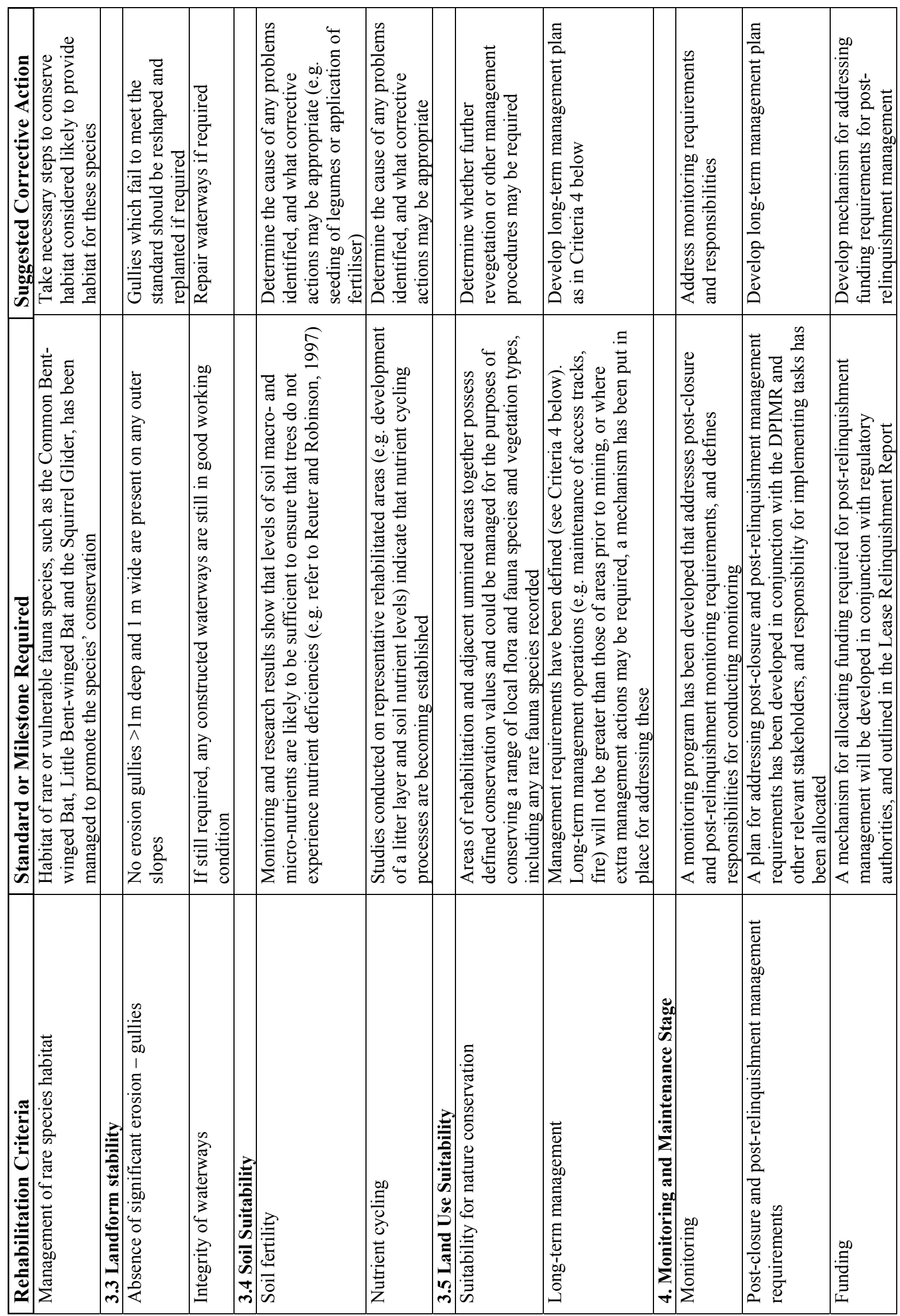

